case registers ${ }^{4}$ and stroke registers. ${ }^{5}$ This week's journal describes the setting up of a district wide diabetic register (p 627). ${ }^{6}$ Disease registers restricted to general practice lists are more limited in their applicability ${ }^{7}$ in not having a natural population base except where efforts are made to achieve representativeness. ${ }^{8}$

The subject of a register will usually reflect its intended uses. Registers have thus been classified as preventive (for example, genetic), disease specific (cancer, psychiatric disease), treatment and follow up (thyroid disease), aftercare (handicap), at risk (occupational hazards), skills and resources (donor panels), and specific information (forensic pathology). ${ }^{9}$

In practice, many disease registers potentially have multiple uses. As well as measuring the frequency and distribution of disease in the population they can detect changes over time, be used to follow up individual patients, enable comparisons of the outcome of different treatment regimens, facilitate monitoring and evaluation of service use, be used for exploring causal associations, be used for clinical research and audit, and help to arrange support for patients.

Before a register is established several key questions must be considered: why the register is required, what disease is being registered, how cases are to be identified and reported, what information will be recorded on each case, how information will be stored and communicated, who will be responsible for producing analyses and servicing requests, who will produce reports, and who will pay. To be of any real value a disease register once established must be maintained well. This means addressing at least two fundamental issues: completeness of ascertainment of cases and validity. ${ }^{10} \mathrm{Un}$ fortunately, this is not always recognised, and the resources set aside to run the register may be insufficient to allow quality control issues to be tackled.

The day to day problems of running a case register are formidable. They include searching for missing records, making good incomplete or inaccurate records, eliminating duplicate entries, resolving coding queries, ironing out computing difficulties, and responding to requests for analyses. Few who have been involved with a register would disagree that success is likely to turn on the presence of a credible senior health care professional with the time, energy, and enthusiasm to galvanise the commitment of the clinicians who will be reporting cases and of a senior administrative officer with an almost pathological degree of obsessiveness.

Without more widespread use of disease registers it is difficult to see how health authorities can meet their responsibility to assess their populations' needs. The decision to establish a register should not, however, be undertaken lightly: it requires proper justification, skilled organisation, adequate resources, and, above all, dedicated and imaginative leadership. A disease register is a long term investment, but it may produce a rich yield that will be just as valuable for those concerned with needs assessment, clinical or epidemiological research, disease prevention, and service evaluation as for those concerned with patient care and support.

LIAM DONALDSON

Regional General Manager and Director of Public Health,

Northern Regional Health Authority,

Newcastle upon Tyne NE6 4PY 1 Secretaries of State for Health, Wales, Northern Ireland, and Scotland. Working for patients.
London: HMSO, 1989. (Cmnd 555.)

2 Office of Population Censuses and Surveys. Cancer statistics: registrations. London: OPCS, 1990 (Series MBI No 18.)

English TAH, Bailey AR, Dark JF, Williams WG. The UK cardiac surgical register 1977-82. BMf 1984;289:1205-8

4 Wing JK, Bransby ER, eds. Psychiatric case registers. London: HMSO, 1970. (Department of Health and Social Security statistical report, series No 8.)

5 Bamford J, Sandercock P, Dennis M, Warlow C, Jones L, McPherson K, et al. A prospective stud of acute cerebrovascular disease in the community: the Oxfordshire community stroke project 1981-1986. 1. Methodology, demography and incident cases of first ever stroke. $\mathcal{F}$ Neurol Neurosurg Psychiatry 1988;51:1373-80.

6 Burnett SD, Woolf CM, Yudkin JS. Developing a diabetic register. BMF 1992;305:627-30.

7 Kemple TJ, Hayter SR. Audit of diabetes in general practice. BMJ 1991;302:451-3.

8 Hofman A, Collette HJA, Bartelds AIM. Incidence and risk factors of Parkinson's disease in the Netherlands. Neuroepidemiology 1989;8:296-9.

9 Weddell JM. Registers and registries: a review. Int $\mathcal{F}$ Epidemiol 1973;2:221-8.

10 Goldberg J, Gelfand HM, Levy PS. Registry evaluation methods: a review and case study. Epidemiologic Reviews 1980;2:210-9.

\title{
Large volume plastic spacers in asthma
}

\section{Should be used more}

The morbidity and mortality from asthma seems to be rising ${ }^{12}$ despite better understanding of the pathogenesis of the disease ${ }^{3}$ more awareness of underdiagnosis and undertreatment, ${ }^{4}$ and a wide choice of effective treatments and delivery systems. Surveys of the severity of symptoms ${ }^{56}$ and inquiries into deaths from asthma ${ }^{7}$ show that we are failing to manage asthma as well as we should. Part of this failure, in treating both chronic symptoms and acute attacks, is due to inhaled drugs not reaching their site of action in the airways. Poor inhaler technique mainly accounts for this, ${ }^{89}$ though poor adherence to prescribed treatment is also a problem.

Pressurised aerosol metered dose inhalers are the mainstay of inhaled treatment for asthma and will probably remain so when environmentally friendly alternatives to the chlorofluorocarbon propellants used in existing devices have been developed. For nearly 10 years we have had the option of prescribing large volume plastic spacers (Nebuhaler and Volumatic) to improve the effectiveness of metered dose inhalers, but many users of aerosols still do not know of their existence or appreciate their value.

The main advantage of large volume spacers is that, compared with the use of a metered dose inhaler alone, they increase the proportion of the dose delivered to the airways while reducing the proportion absorbed into the body. An in vivo radiotracer study showed that a large volume spacer deposited $21 \%$ of the dose in the lungs and $16 \%$ in the oropharynx, with $56 \%$ remaining in the spacer. ${ }^{10}$ Metered dose inhalers used alone deposit $10-15 \%$ in the lungs with about $80 \%$ in the oropharynx. ${ }^{10}$ Dry powder devices similarly deposit $10-15 \%$ of the dose in the lungs and $70-80 \%$ in the oropharynx. ${ }^{12}{ }^{13}$ Clinical studies have shown that using large volume spacers with metered dose inhalers is more effective than using metered dose inhalers on their own. ${ }^{14} 15$ The relative superiority of the spacer in achieving lung deposition of inhaled drug is likely to be even greater during an asthma attack.

The better pattern of deposition achieved with spacers not only improves efficacy but may also reduce adverse effects, such as oral candidiasis, dysphonia, ${ }^{16}$ and suppression of the hypothalamic-pituitary-adrenal axis, ${ }^{17} 18$ which may occur with high doses of inhaled steroids. Clinically important adverse effects of inhaled steroids are rare at lower doses, ${ }^{19}$ but reducing the dose to the minimum consistent with good control of symptoms is preferable.

Large volume spacers are easy to use and largely overcome the problems of poor technique associated with use of metered 
dose inhalers. This is especially valuable in treating elderly people and children and is a more economical response to the problem than prescribing the more costly dry powder devices. Wheezy infants have been successfully treated with a large volume spacer with a soft plastic face mask attachment ${ }^{2021}$; many 2 year olds and most 3 year olds can learn to use spacers effectively without a mask.

Large volume spacers are at least as effective as nebulisers for giving high doses of bronchodilators in acute severe asthma. Unlike nebulisers they are widely available, ${ }^{22}{ }^{23}$ cheap, easily portable, and do not require electricity. Less severe attacks of wheezing will often respond to several puffs of a bronchodilator given slowly through a spacer one puff at a time, one puff per minute, until the wheezing is relieved, side effects of tremor and tachycardia are experienced, or a stated maximum number of puffs has been given. This advice should be set out clearly in a comprehensive self management plan. ${ }^{24}$

Every asthmatic patient who uses a metered dose inhaler should have a large volume spacer and know how to use it. Steroid aerosols should preferably be inhaled through a spacer whatever the dose both in adults and children. General practitioners should have a spacer in their surgery for demonstration purposes and one in the boot of their car for treating acute attacks, with a spare for leaving with patients who need one in the middle of the night. The advantages of large volume spacers could feature more prominently in future national and local asthma management guidelines, and pharmaceutical companies could devote part of their advertising budget to making patients and doctors more aware of the role of these devices. Package inserts for metered dose inhalers should inform patients of the value of the volume spacers in enhancing the effectiveness of inhalers, especially during exacerbations.

By reducing the enormous waste of inhaled drugs that results from poor inhaler technique, these measures would reduce the respiratory prescribing costs. More importantly, they should improve the effectiveness and efficiency of the management of asthma and so help to reduce morbidity, the need for admission to hospital, and perhaps even mortality.

General Practitioner,

DUNCAN KEELEY

Thame,

Oxfordshire OX9 3JZ

Burr M, Butland B, King S, Vaughan-Williams E. Changes in asthma prevalence; two surveys 15 years apart. Arch Dis Childhood 1989;64:1452-6.

Burney PGJ. Asthma mortality in England and Wales: evidence for a further increase. Lancet 1986 ii: $323-6$.

Holgate ST, Finnerty JP. Recent advances in understanding the pathogenesis of asthma and its clinical implications. $Q \mathcal{F}$ Med 1988;66:5-19.

4 Speight A, Lee D, Hay E. Underdiagnosis and undertreatment of asthma in childhood. BM 1983 286:1253-6.

Turner-Warwick M. Nocturnal asthma: a study in general practice. I $R$ Coll Gen Pract 1989 39:239-43.

6 Jones $\mathrm{K}$, Bain D, Middleton $M$, Mullee $M$. Correlates of asthma morbidity in primary care. $B M$ 1992;304:361-4.

British Thoracic Association. Death from asthma in two regions of England. BMf 1982, 285:1251-5.

8 Crompton G. Problems patients have using pressurised aerosol inhalers. Eur $\mathcal{Y}$ Respir Dis 1982; 63 (suppl 119): 101-4.

9 Hilton $\mathrm{S}$. An audit of inhaler technique among asthma patients of 34 general practitioners. $\mathrm{Br} f \mathrm{G}$ Pract 1990;40:505-6.

10 Newman S. Millar A, Lennard Jones T, Moren F. Clarke S. Improvement of pressurised aeroso deposition with Nebuhaler spacer device. Thorax 1984;39:935-41.

11 Newman S, Pavia D, Garland N, Clarke SW. Effects of various inhalation mods on the deposition of radioactive pressured aerosols. Eur $\mathcal{F}$ Respir Dis 1982;63(suppl 119):57-65.

12 Newman S, Moren F, Trofast E, Talaee N, Clarke S. Deposition and clinical efficacy of terbutalin sulphate from Turbuhaler, a new multi-dose powder inhaler. Eur Respir $\mathcal{f}$ 1989;2:247-52.

13 Newman S Moren F, Trofast E, Talaee N, Clarke S. Terbutaline sulphate Turbuhaler: effect of inhaled flow rate on drug deposition and efficacy. International fournal of Pharmaceutics 1991;74:209-13.

14 Tobin M, Jenouri G, Danta I, Kim C, Watson H, Sackner M. Response to bronchodilator drug administration by a new reservoir aerosol delivery system and a review of other auxiliary delivery system. Am Rev Respir Dis 1982;126:670-5.

15 Cushley $M$, Lewis $R$, Tattersfield A. Comparison of three techniques of inhalation on the airway response to terbutaline. Thorax 1983;38:908-13.

16 Toogood J, Jennings B, Greenway R, Chuang L. Candidiasis and dysphonia complicatin beclomethasone treatment of asthma. I Allerg Clin Immunol 1980;65:143-53.

17 Brown $P$, Blundell G, Greening A Crom systemic effects of high dose inhaled corticosteroids? Thorax 1990;45:736-9.

18 Prahl P, Jensen T. Decreased adrenocortical suppression utilising the nebuhaler for inhalation of steroid aerosols. Clin Allerey 1987;17:393-8.

19 Geddes D. Inhaled corticosteroids: benefits and risks. Thorax 1992;47:404-7

20 O'Callaghan C, Milner A, Swarbrick A. Spacer device with face mask attachment for giving bronchodilators to infants with asthma. BMf 1989;298:160-1.

21 Bisgaard H, Munck S, Nielsen J, Peterson W, Ohlsson S. Inhaled budesonide for treatment of recurrent wheezing in early childhood. Lancet 1990;336:649-51.

22 Morgan M, Singh B, Frame M, Williams S. Terbutaline aerosol given through a pear spacer in acute severe asthma. $B M$ F 1982;285:849-50.

23 Fuglsang G, Pedersen S. Comparison of Nebuhaler and nebuliser treatment of acute severe asthma in children. Eur f Respir Dis 1986;69:109-13.

24 Beasley R, Cushing M, Holgate ST. A self management plan in the treatment of adult asthm Thorax 1989;44:200-4.

\section{Health checks for people over 75}

\section{The doubts persist}

The government introduced health checks for people over 75 with more of an eye to client satisfaction ${ }^{12}$ than to the findings of research. ${ }^{3}$ General practitioners, who are contractually obliged to provide the checks, remain uncertain of their purpose and content, what constitutes competence and satisfactory performance, and who should provide them. Two papers in this week's journal illustrate this uncertainty (p 619, ${ }^{4}$ p 621 $1^{5}$ ).

What is the evidence that screening elderly people improves their health? Four randomised trials have examined the question. Using a nurse to screen people over 70 in an affluent practice, Tulloch and Moore showed that screening did not change the prevalence of illness, although patients' morale and referral rates rose and admission rates fell. ${ }^{6}$ Using a health visitor to assess people over 70, Vetter et al showed in an urban practice that annual screening reduced mortality, though not morbidity. ${ }^{7}$ A Danish study showed that three monthly visits by a nurse to people over 75 reduced admissions, emergency calls, and mortality. ${ }^{8}$ McEwan et al found that domiciliary visits by a nurse to people over 75 improved morale but no other measures of health.
The failure of screening to improve morbidity does not mean that it is a waste of time and effort. Screening improves the quality of life. ${ }^{6-10}$ In any case, the effects of screening on morbidity have yet to be fully evaluated: so far, easily defined measures of outcome, favouring the detection of medical disorders, have usually been chosen in preference to sensitive

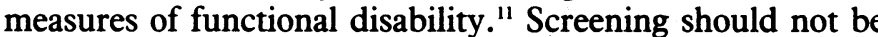
regarded as having failed if the failure has been in offering effective treatment or advice.

The current consensus is that screening is useful in identifying functional disabilities, which may have received little or no medical attention. The prevalence of functional problems in elderly people-especially problems with hearing, ${ }^{12}{ }^{13}$ mobility, ${ }^{12}$ continence,${ }^{12}$ vision, ${ }^{14}$ teeth,${ }^{15}$ and cognitive function ${ }^{16}$-is high. For how many of these and other health problems does good evidence exist for the effectiveness of screening? The benefits of treating hypertension in elderly people are clear: the protection it offers against stroke and myocardial infarction justifies the treatment of those up to $80^{18}$ and even beyond. ${ }^{19}$ Given our limited resources, screening people at 75 and 78 therefore seems justified. 